\title{
$\infty$
}

\section{Effect of the Cu Bottom Layer on the Properties of Ga Doped ZnO Thin Films}

\author{
Daeil $\mathrm{Kim}^{\dagger}$ \\ School of Materials Science and Engineering, University of Ulsan, Ulsan 680-749, Korea
}

Received April 29, 2012; Accepted June 5, 2012

\begin{abstract}
Ga doped $\mathrm{ZnO}(\mathrm{GZO}) /$ copper $(\mathrm{Cu})$ bi-layered film was deposited on glass substrate by RF and DC magnetron sputtering and then the effect of the Cu bottom layer on the optical, electrical and structural properties of GZO films were considered. As-deposited $100 \mathrm{~nm}$ thick GZO films had an optical transmittance of $82 \%$ in the visible wavelength region and a sheet resistance of $4139 \Omega / \square$, while the $\mathrm{GZO} / \mathrm{Cu}$ film had optical and electrical properties that were influenced by the $\mathrm{Cu}$ bottom layer. GZO films with $5 \mathrm{~nm}$ thick $\mathrm{Cu}$ film show the lower sheet resistance of $268 \Omega / \square$ and an optical transmittance of $65 \%$ due to increased optical absorption by the $\mathrm{Cu}$ metallic bottom layer. Based on the figure of merit, it can be concluded that the thin $\mathrm{Cu}$ bottom layer effectively increases the performance of GZO films as a transparent and conducting electrode without intentional substrate heating or a post deposition annealing process.
\end{abstract}

Keywords: GZO, Cu, Thin film, Magnetron sputtering, Surface roughness

\section{INTRODUCTION}

The rapidly increasing use of transparent and conductive oxide (TCO) films for large-area displays and solar cells has prompted the development and study of inexpensive TCO materials, which exhibit appropriate optical and electrical properties.

Recently, $\mathrm{Al}$ and $\mathrm{Ga}$ doped $\mathrm{ZnO}$ films have attracted attention due to their high optical transmittance in the visible wavelength range, low electrical resistivity, and relatively low cost compared to Sn-doped indium oxide (ITO) [1,2] films.

However, in most metal doped $\mathrm{ZnO}$ films, relatively high substrate temperatures are required in order to obtain the necessary electrical conductivity and optical transmittance in the visible wavelength region $[3,4]$. Thus, for certain applications, such as flexible optoelectronic devices, high substrate temperatures are undesirable due to the low thermal resistivity for polymer substrates $[5,6]$. One way to improve the optical and electrical properties of the TCO films without substrate heating is to use

${ }^{\dagger}$ Author to whom all correspondence should be addressed:

E-mail: dkim84@ulsan.ac.kr

Copyright $\odot 2012$ KIEEME. All rights reserved. This is an open-access article distributed under the terms of the Creative Commons Attribution Non-Commercial
License (http:///creativecommons. org/licenses/by-nc/3.0) which permits unrestricted noncommercial use (a)
$\mathrm{TCO} / \mathrm{metal} / \mathrm{TCO}$ structures that have lower resistivity compared to TCO single layer films of the same thickness [7-9].

In this study, transparent and conducting $\mathrm{GZO} / \mathrm{Cu}$ bi-layered films were deposited on a glass substrate without intentional substrate heating by RF and DC magnetron sputtering and then the effect of the Cu bottom layer on the optical, electrical and structural properties of the films were investigated.

\section{EXPERIMENTS}

$\mathrm{GZO} / \mathrm{Cu}$ bi-layered films were deposited on a glass (Corning 1737) substrate without intentional substrate heating by RF and DC magnetron sputtering equipped with two cathodes. RF (13.56 $\mathrm{MHz}$ ) and DC power were applied to the GZO (purity; 99.99\%) and $\mathrm{Cu}$ (purity; 99.9\%) targets, respectively. During deposition, the substrate temperature was monitored using a K-type thermocouple in direct contact with the substrate surface and was maintained at $60^{\circ} \mathrm{C}$.

Prior to deposition, the chamber was evacuated to a pressure of $2.0 \times 10^{-4} \mathrm{~Pa}$. Sputtering was performed at $1 \times 10^{-1} \mathrm{~Pa}$ in argon (Ar) and the deposition distance between the target and substrate was maintained at $7 \mathrm{~cm}$. By controlling the deposition time and 
Table 1. Deposition conditions of GZO and $\mathrm{Cu}$ thin films.

\begin{tabular}{lcc}
\hline & $\mathrm{GZO}$ & $\mathrm{Cu}$ \\
\hline Base pressure $(\mathrm{Pa})$ & $1.5 \times 10^{-4}$ & $1.5 \times 10^{-4}$ \\
Deposition pressure $(\mathrm{Pa})$ & $1.8 \times 10^{-2}$ & $1.5 \times 10^{-2}$ \\
Power density $\left(\mathrm{W} / \mathrm{cm}^{2}\right)$ & $\mathrm{RF}, 3.5$ & $\mathrm{DC}, 2.3$ \\
Deposition rate $(\mathrm{nm} / \mathrm{min})$ & 10 & 20 \\
$\mathrm{Ar} / \mathrm{O}_{2}$ gas flow rate & $5 / 0.03$ & 5 \\
\hline
\end{tabular}

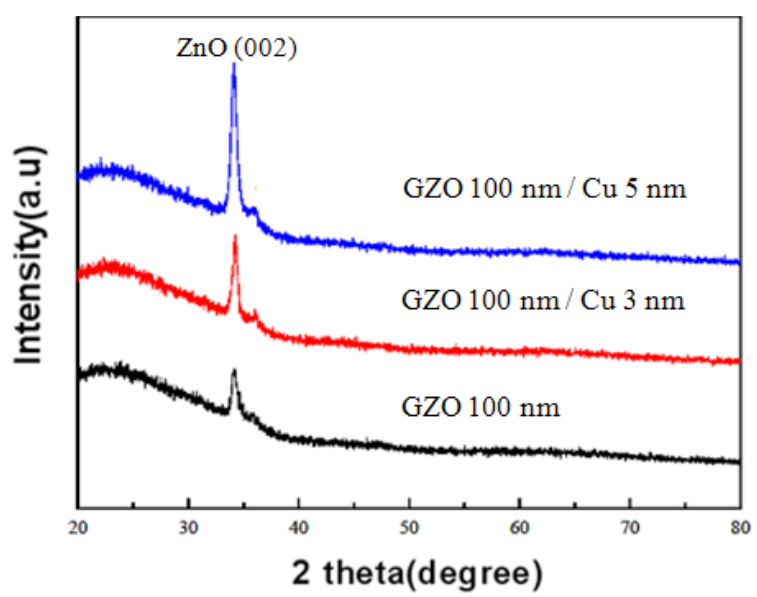

Fig. 1. The XRD patterns of GZO and GZO/Cu bi-layered films.

sputtering power, the thickness for GZO film was maintained at $100 \mathrm{~nm}$, while the thickness for the Cu bottom layer was set at 3 and $5 \mathrm{~nm}$, respectively. For comparison, $100 \mathrm{~nm}$ thick GZO single layer films were also deposited under the same deposition conditions. Table 1 shows the deposition parameters and conditions in this study.

After deposition, film thickness was confirmed with a surface profilometer, and the crystallization of the films was observed with high resolution X-ray diffraction (XRD, X' pert Pro MRD, Philips at Korea Basic Science Institute, Daegu Center). The root mean square (RMS) roughness was analyzed using atomic force microscopy (AFM, XE-100, Park Systems). In addition, optical and electrical properties were assessed using a four-point probe (Loresta-EP, MCP-T360, Mitsubishi) and a UV-Vis. spectrophotometer (Cary 100 Cone, Varian), respectively. The glass substrates showed a $92 \%$ optical transmittance in the visible wavelength range. The performance of the $\mathrm{GZO}$ and $\mathrm{GZO} / \mathrm{Cu}$ films as transparent conducting films was evaluated using the figure of merit (FOM) [10].

\section{RESULTS AND DISCUSSION}

In order to evaluate the performance of the $\mathrm{GZO} / \mathrm{Cu}$ films, structural characterization is very important since the optical and electrical properties of the films are strongly dependent on the microstructure. Recently, Sun et al. investigated the initial growth mode of ITO on glass substrate over a substrate temperature range of $20-400{ }^{\circ} \mathrm{C}$ [11]. They suggested that an amorphous structure ITO film was formed at substrate temperatures below $150^{\circ} \mathrm{C}$.

Figure 1 is the XRD patterns of GZO and GZO/Cu bi-layer films deposited without intentional substrate heating. For all of the films, the diffraction peaks in the XRD pattern were identified as (002) plane of a $\mathrm{ZnO}$ film.

Although the $\mathrm{Cu}$ bottom layer did not show any diffraction peak in the pattern, it is observed that as the $\mathrm{Cu}$ thickness in-
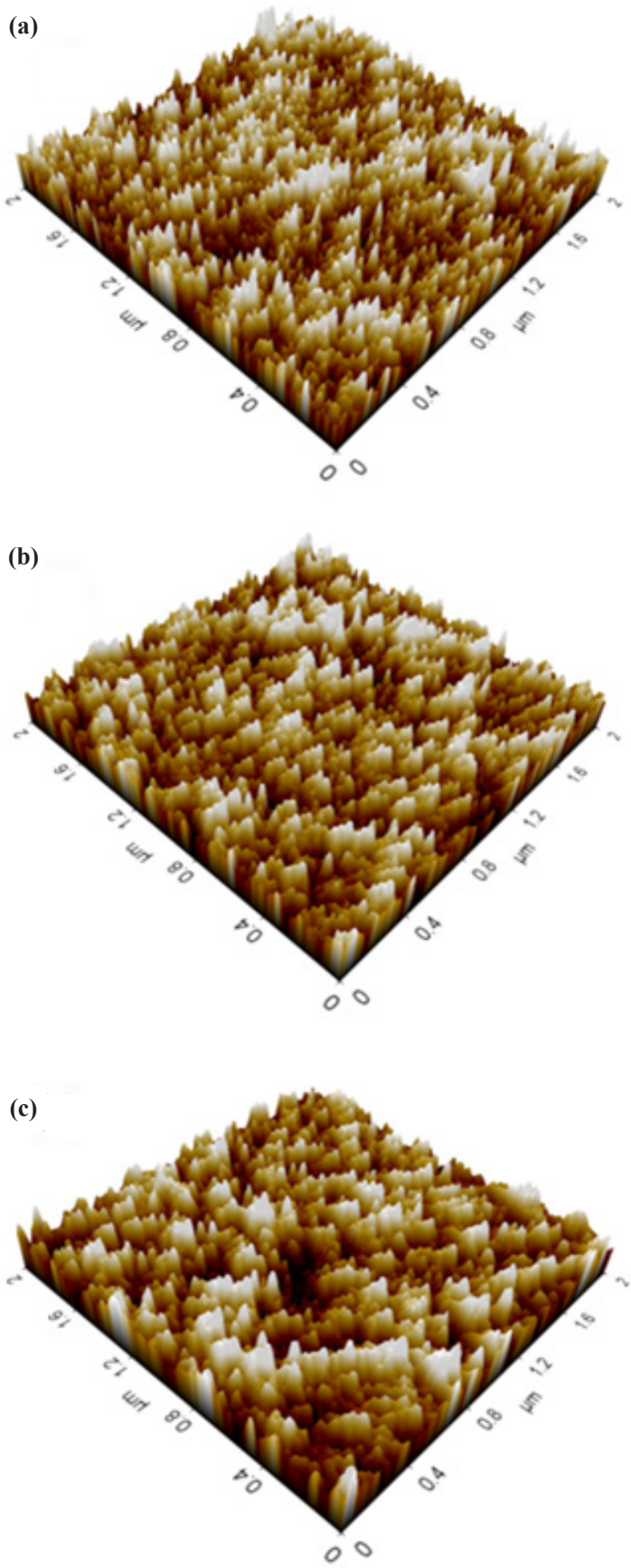

Fig. 2. AFM image of (a) GZO100 nm(RMS roughness; $3.2 \mathrm{~nm}$ ), (b) GZO $100 \mathrm{~nm} / \mathrm{Cu} 3 \mathrm{~nm}$ (RMS roughness; $3.4 \mathrm{~nm}$ ), and (c) GZO 100 $\mathrm{nm} / \mathrm{Cu} 5 \mathrm{~nm}$ films (RMS roughness; $3.9 \mathrm{~nm}$ ).

creased, the peak intensity of $\mathrm{ZnO}(002)$ increased proportionally.

Thus, it is supposed that the Cu bottom layer may enhance the crystallization of the upper GZO films. In a previous study, Y. Kim reported similar results that in ITO/Au bi-layered films, the crystallization of the ITO film is promoted by the Au bottom layer [12].

Figure 2 shows the three-dimensional AFM images of asdeposited $\mathrm{Cu}$ and $\mathrm{GZO} / \mathrm{Cu}$ films. The RMS roughness of the asdeposited $3 \mathrm{~nm}$ thick $\mathrm{Cu}$ thin film was $0.30 \mathrm{~nm}$ and $0.52 \mathrm{~nm}$ for 5 $\mathrm{nm}$ thick $\mathrm{Cu}$ thin film was $0.52 \mathrm{~nm}$, respectively. With increasing the thickness of the $\mathrm{Cu}$ bottom layer, the RMS roughness of GZO/ $\mathrm{Cu}$ films was increased. The higher RMS roughness of $3.9 \mathrm{~nm}$ was obtained from the GZO $100 \mathrm{~nm} / \mathrm{Cu} 5 \mathrm{~nm}$ bi-layered films. 


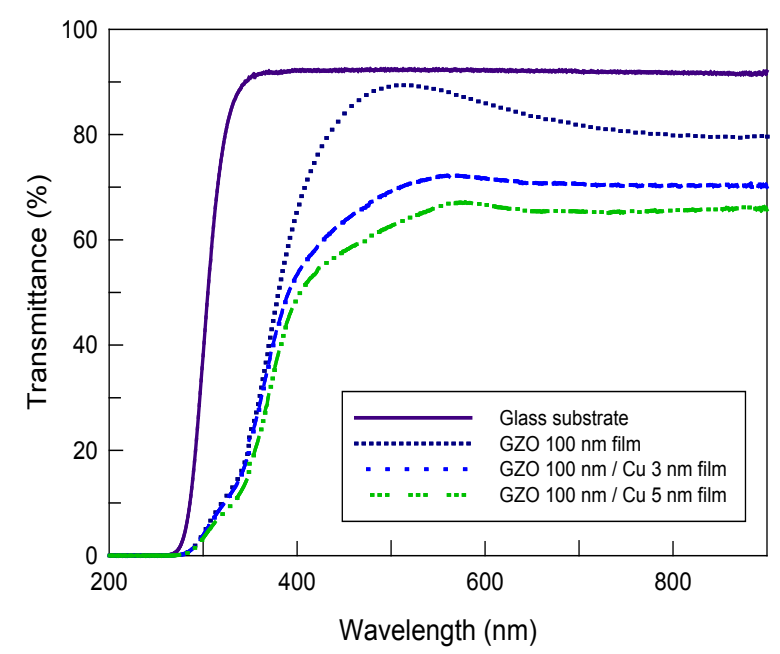

Fig. 3. Optical transmittance of GZO and GZO/Cu bi-layered films.

As shown in Fig. 2, though the thin Cu bottom layer had a relatively flat surface morphology, it increased the surface roughness of the GZO film effectively in the bi-layered films. Since the rough surface morphology resulted in a wider film surface area, it can be inferred that the effect of the $\mathrm{Cu}$ bottom layer on the surface roughness is favorable for solar cells and gas sensor applications regarding GZO films.

Figure 3 shows the optical transmittance for a wavelength range of 300-900 $\mathrm{nm}$. The GZO single layer films had optical transmittances in the visible wavelength region of $82 \%$. The GZO $100 \mathrm{~nm} / \mathrm{Cu} 3 \mathrm{~nm}$ and GZO $100 \mathrm{~nm} / \mathrm{Cu} 5 \mathrm{~nm}$ films had optical transmittances in the visible wavelength region of $70 \%$ and $65 \%$, respectively. The optical absorption at the interface between the GZO and $\mathrm{Cu}$ films may reduce the optical transmittance of the $\mathrm{GZO} / \mathrm{Cu}$ films and in addition, the rougher surface of GZO films with a $5 \mathrm{~nm}$ thick $\mathrm{Cu}$ bottom layer results in lower optical transmittance due to the increase of absorption regarding the incident light at the film surface as shown Fig. 3.

Table 2 shows the optical and electrical properties of the films. The GZO/Cu films had a lower sheet resistance compared to that of the GZO single layer films. The figure of merit (FOM) is an important index for evaluating the performance of transparent conducting oxide (TCO) films [13]. The FOM is defined as $F O M=T^{10} / R_{s}$, where $T$ is the optical transmittance and Rs is the sheet resistance. Although the optical transmittance of GZO films is deteriorated with the $\mathrm{Cu}$ bottom layer, $\mathrm{GZO} / \mathrm{Cu}$ films have the one order lower sheet resistance compared to that of the GZO single layer films. Thus, the FOM reached a maximum of $5.0 \times 10^{-5} \Omega^{-1}$ for the GZO $100 \mathrm{~nm} / \mathrm{Cu} 5 \mathrm{~nm}$ films, which is greater than the FOM for the GZO single layer films and the $\mathrm{In}_{2} \mathrm{O}_{3}$ films prepared in a previous study [14]. It is supposed that the enormous electrons in the $\mathrm{Cu}$ bottom layer may enhance the carrier density and enhance the electrical properties of the $\mathrm{GZO} / \mathrm{Cu}$ films. Since the higher FOM value indicates better quality of TCO films, it is supposed that the GZO films with $5 \mathrm{~nm}$ thick $\mathrm{Cu}$ bottom layers will likely perform better in TCO applications than GZO single layer films.
Table 2. The comparison of figure of merit (FOM, $\left.\Omega^{-1}\right)$.

\begin{tabular}{cccc}
\hline \multirow{2}{*}{ Films } & $\begin{array}{c}\text { Sheet resistance } \\
(\Omega / \square)\end{array}$ & $\begin{array}{c}\text { Transmittance } \\
(\%)\end{array}$ & $\begin{array}{c}\text { FOM } \\
(\Omega-1)\end{array}$ \\
\hline \hline GZO & 4,139 & 82 & $3.3 \times 10^{-5}$ \\
GZO/Cu 3 nm & 800 & 70 & $3.5 \times 10^{-5}$ \\
GZO/Cu 5 nm & 268 & 65 & $5.0 \times 10^{-5}$ \\
\hline
\end{tabular}

\section{CONCLUSIONS}

Both GZO and GZO/Cu bi-layered films were deposited on glass substrates using RF and DC magnetron sputtering. The optical and electrical properties were dependent on the $\mathrm{Cu}$ bottom layer in the $\mathrm{GZO} / \mathrm{Cu}$ films.

Figure of merit for the GZO $100 \mathrm{~nm} / \mathrm{Cu} 5 \mathrm{~nm}$ films reached a maximum value of $4.3 \times 10^{-5} \Omega^{-1}$, which was greater than that of the GZO single layer films. This result indicates that the $5 \mathrm{~nm}$ thick $\mathrm{Cu}$ bottom layer in the $\mathrm{GZO} / \mathrm{Cu}$ films results in better performance compared to conventional GZO single layer films.

\section{REFERENCES}

[1] H. Yano, D. Kouro, N. Sasaki, S. Muramatsu, Sol. Ener. Mater. Sol. Cells 93, 976 (2009) [DOI: dx.doi.org/10.1016/ j.optlaseng.2011.03.003].

[2] Z. You, J. Dong, Microelectron. J, 38, 108 (2007) [DOI: dx.doi. org/10.1016/j.mejo.2006.09.019].

[3] S. Cho, H. Kim, Mater. Sci. Eng. B, 172, 327 (2010) [DOI: dx.doi. org/10.1016/j.mseb.2010.06.008].

[4] C. Huang, D. Chen, C. Hsu, Ceramics International 38, 1057 (2012) [DOI: dx.doi.org/10.1016/j.ceramint.2011.08.031].

[5] U. Betz, M. Olsson, J. Martly, M. Escola, Surf. Coat. Technol. 200, 5751 (2006) [DOI: dx.doi.org/10.1016/j.surfcoat.2005.08.144].

[6] C. Guillén, J. Herrero, Vacuum 80, 615 (2006) [DOI: dx.doi. org/10.1016/j.vacuum.2005.10.006].

[7] D. Kim, Appl. Surf. Sci. 218, 71 (2003) [DOI: dx.doi.org/10.1016/ S0169-4332(03)00542-7].

[8] K. Maki, N. Komiya, A. Suzuki, Thin Solid Films 445, 224 (2003) [DOI: dx.doi.org/10.1016/j.tsf.2003.08.021].

[9] D. Kim, D. Ma, N. Lee, Jpn. J. Appl. Phys. 43, 1536 (2004) [DOI: dx.doi.org/10.1143/JJAP.43.1536]

[10] J. Park, J. Chae, D. Kim, J. Alloy. Comp. 478, 330 (2009) [DOI: dx.doi.org/10.1016/j.jallcom.2008.11.065].

[11] X. Sun, H. Huang, H. Kwok, Appl. Phys. Lett. 68, 2663 (1996) [http://dx.doi.org/10.1063/1.116274].

[12] Y. S. Kim, J. H. Park, D. Kim, Vacuum. 82, 574 (2008) [DOI: dx.doi.org/10.1016/j.vacuum.2007.08.011].

[13] G. Haacke, J. Appl. Phys. 47, 4086 (1976) [DOI: dx.doi. org/10.1063/1.323240].

[14] Y. Kong, Y. Lee, S. Huh, H. Lee, M. Seo, Y. Kim, D. Kim, Kor. J. Mater. Res. 22, 24 (2012) [DOI: dx.doi.org/10.3740/ MRSK.2012.22.1.024]. 